\title{
GIDA ATIKLARINDAN AKTİF KARBON ÜRETİMİ VE AKTİF KARBONUN GIDA ENDÜSTRİSINDE UYGULAMALARI
}

\author{
Eda Ülkeryıldız Balçık ${ }^{1}$, Mehmet Torun ${ }^{2}$, Hilal Şahin Nadeem ${ }^{1 *}$ \\ ${ }^{1}$ Adnan Menderes Üniversitesi, Mühendislik Fakültesi, Gıda Mühendisliği Bölümü, Aydın, Türkiye \\ ${ }^{2}$ Akdeniz Üniversitesi, Mühendislik Fakültesi, Gıda Mühendisliği Bölümü, Antalya, Türkiye
}

Geliş / Received: 10.08.2019; Kabul / Accepted: 09.12.2019; Online bask1 / Published online: 17.02.2020

Ülkeryıldız Balçık, E., Torun, M., Şahin Nadeem, H. (2020). Gıda atıklarından aktif karbon üretimi ve aktif karbonun gida endüstrisinde uygulamalar1. GIDA (2020) 45 (2): 217-229 doi: 10.15237/gida.GD19127

Ülkeryldiz. Balçle, E., Torun, M., Sabin Nadeem, H. (2020). Production of active carbon from food wastes and the applications of active carbon in food industry. GIDA (2020) 45 (2): 217-229 doi: 10.15237/gida.GD19127

ÖZ

Aktif karbonlar, yüksek gözenek hacimleri $\left(0,5-1,5 \mathrm{~cm}^{3} / \mathrm{g}\right)$ ve geniş yüzey alanları $\left(500-2000 \mathrm{~m}^{2} / \mathrm{g}\right)$ ile hem fiziksel hem de kimyasal olarak mükemmel adsorban malzemeler olarak tanımlanmaktadır. Aktif karbonlar ayırma, saflaştırma, uzaklaştırma ve geri kazanım süreçlerinde, tıp, çevre, kimya, enerji, metalurji, tekstil ve gıda gibi alanlarda kullanılmaktadır. Aktif karbonların, karbon içeriği yüksek, inorganik madde içeriği düşük çeşitli biyokütle atıklarından üretilebilmesi ve rejenerasyonla tekrar kullanılabilmesi avantaj sağlamaktadır. Gıda endüstrisinde aktif karbon; içecek endüstrisinde renk, koku ve tat düzenleyici, şeker-şurup endüstrisinde renk ağartıcı, klimakterik meyve ve sebzelerde raf ömrü kontrolü, organik madde adsorplama veya besinsel olmayan toksik madde uzaklaştırma, kızartma yağı ve içme suyu arıtımı gibi uygulamalarda kullanılmaktadır. Aktif karbonların gıda endüstrisindeki güncel uygulamaları ise; aerobik sindirim prosesleri, modifiye atmosfer uygulamaları, saflaştırma, yeni nesil antimikrobiyal ajan üretimi, uçucu organik bileşen uzaklaşırıma ve aroma geri kazanımı çalışmalarıdır. Ayııca, yüksek verimli ayırma ve saflaştırma için elektrokimyasal gıda sensörleri ve elektromanyetik aktif karbonlar üretilmektedir.

Anahtar Kelimeler: aktif karbon, gıda atıkları, gıda endüstrisi, ayrışırma, saflaşırıma

\section{PRODUCTION OF ACTIVE CARBON FROM FOOD WASTES AND THE APPLICATIONS OF ACTIVE CARBON IN FOOD INDUSTRY}

\begin{abstract}
Activated carbon is an excellent physicochemical adsorbent with high porous volumes $\left(0.5-1.5 \mathrm{~cm}^{3} / \mathrm{g}\right)$ and large surface areas $\left(500-2000 \mathrm{~m}^{2} / \mathrm{g}\right.$ ). It has been used in medicine, environment, chemistry, energy, metallurgy, textile and food in separation, purification, removal and recovery processes. It can be produced from various biomass wastes with high carbon and low inorganic material content that is recyclable. In the food industry, it is used as color, odor and taste regulator in beverages, color bleaching in sugar-syrup, shelf-life control in climacteric fruits and vegetables, adsorption of organics or removal of non-nutrient toxic substances, treatments of frying oil and drinking water. Their novel applications in food industry include the aerobic digestion, modified atmospheres, purification, novel antimicrobial agent production, volatile organic component removal, aroma recovery studies, electrochemical food sensors and electromagnetic materials for the efficient separation and purification.
\end{abstract}

Key words: activated carbon, food waste, food industry, separation, purification

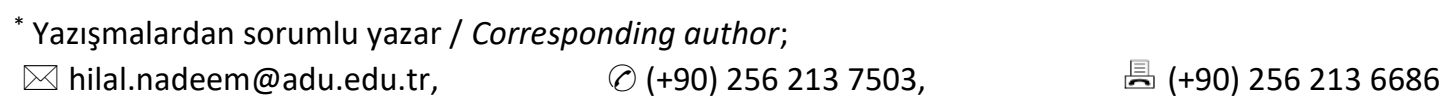

Eda Ülkeryıldız Balçık; ORCID no: 0000-0003-1424-1043

Mehmet Torun; ORCID no: 0000-0002-6287-2993

Hilal Şahin Nadeem; ORCID no: 0000-0003-2516-7846 


\section{GİRİ̧̧}

Aktif karbon, karbon atomlarının hibritleşme ve bağ yapisı ile oluşturduğu, allotrop yapisına göre grafitik olmayan formda olup, yüksek karbon içeriğine sahip maddelerden aktivasyon prosesi ile elde edilen, gelişmiş gözenek yapısı ve geniş yüzey alanı ile adsorpsiyon uygulamalarında iyi bir adsorban malzeme olarak kullanilan amorf yapilı bir maddedir (Aky1ldız, 2007; Dermanl1, 2006; Menderez-Diaz vd., 2006). Aktif karbonların yüzeyi altıgen olarak bağlanmış karbon atomları içeren mikrokristalinlerin oluşturduğu düzlemlerden oluşmaktadır. Kristalinlerin düzenli karbon bağları aktivasyon işlemi sırasında bozulmakta ve bazı mikrokristalin yapilar uzaklaşmaktadır. Karbon mikrokristalitleri arasındaki boşluklar, grafitik düzlemlerin içine ve paraleline olan çatlaklar ile gözenekli yap1 oluşturmaktadır. Gözenek çap1 IUPAC (Uluslararası Temel ve Uygulamalı Kimya Birliği) tarafindan 2 nm'den küçük mikrogözenek, 2-50 $\mathrm{nm}$ arasında mezogözenek ve $50 \mathrm{~nm}$ 'den büyük makro gözenek olmak üzere üç gruba ayrilmaktadır (Menderez-Diaz vd., 2006). Uygulamada, yüksek oranda gaz ve buhar adsorpsiyonu için mikro gözenekler tercih edilirken, çözelti ve sıvı adsorpsiyonu için mezo ve makro gözenekler tercih edilmektedir. Yapısındaki gözeneklerle adsorplanacak molekül büyüklügünün elverişine göre düşük sıcaklıklarda ve hizlı bir difüzyon ile fiziksel adsorpsiyon gerçekleşirken, yüksek yüzey reaktivitesi sayesinde moleküllerin kendi iç kısımlarına çekilmesi ve bağlanması kimyasal adsorpsiyon ile gerçekleşmektedir. Fiziksel adsorpsiyonda gözenekli yap1 içindeki karbona güçlü fiziksel bağlar (Van der Waals ve London kuvvetleri) etkinken, kimyasal adsorpsiyonda yüzey fonksiyonel gruplarına göre daha güçlü kimyasal bağlar etkindir (Türkmen, 2015). Aktif karbonların yüzey kimyası, oksijen fonksiyonelliğini oluşturmak için farklı maddelerle oksidasyon yoluyla 1sıl işlemle aktive edilmektedir. Karbon yüzeyinde bulunabilecek oksijen içeren önemli yüzey gruplarn; karboksilik gruplar, fenolik hidroksil gruplar, quinon tipi karbonil gruplar, normal laktonlar, floressenitip laktanlar, karboksilik asit anhidritler, siklik peroksitlerdir (Menderez-Diaz vd., 2006; Akylldı, 2007).
İşlevsel grupların aktif karbonların adsorpsiyon kapasitesinde etkili olan parametreleri; yüzey yükünü değiştirmeleri, hidrofilik-hidrofobik yapıları ve asidik-bazik karakterlerini etkilemesidir (Menderez-Diaz vd., 2006). Aktif karbonların kalitesini belirleyen en belirgin özellikleri adsorpsiyon kapasitesidir. Adsorpsiyon kapasitesi parametreleri; adsorban hammaddesinin kimyasal ve fiziksel özellikleri, adsorbanın çözünürlüğü, sicaklık ve pH'dır (Anonymous, 2002; Türkmen, 2015). Adsorpsiyon testlerinde yüzey alan1, adsorban olarak Azot $\left(\mathrm{N}_{2}\right)$ veya karbondioksit $\left(\mathrm{CO}_{2}\right)$ gazı kullanilarak BET (Brunauer-EmetTeller) yöntemi ile $\mathrm{m}^{2} / \mathrm{g}$ cinsinden belirlenirken, adsorpsiyon kapasitesi iyot adsorpsiyonu, metilen mavisi adsorpsiyonu veya fenol adsorpsiyonu testleri ile belirlenmektedir (Dermanlı, 2006; Akyıldız, 2007).

Aktif karbonların kalitesi ve özellikleri belirlenirken sadece yüzey karakteristiklerine bakarak sinıflandırma yapmak yeterli değildir. Kullanım alanına göre adsorplanan molekülün büyüklüğü değiştikçe yüzey alanı da değişmektedir. Ayrıca karbonizasyon ve aktivasyon şartlarına göre aktif karbonun gözenek boyut dağılımı, şekli ve hacmi değişim göstermektedir (Türkmen, 2015). Fiziksel olarak aktif karbonlar: toz aktif karbon (0,15- 0,25 mm'den daha küçük partiküllü), granüler aktif karbon (1-5 mm arasında partiküllü), pellet aktif karbon (basınçla sıkıştırılmışs silindirik 0,8-5 mm partiküllü), küresel aktif karbon (petrol kaynaklı 0,35-0,80 mm küresel partiküllü) ve aktif karbon fiberleri (sentetik liflerden isıl işlemle karbonize olmuş ve termal aktivasyon ile üretilmiş) şeklinde beş grupta sınıflandırılmaktadır (Menderez-Diaz vd., 2006; Akylldız, 2007; Türkmen, 2015)

\section{Aktif Karbon Üretimi}

Aktif karbon üretiminde yüksek karbon (\% 40-80) ve düşük inorganik madde içeriğine sahip hammaddeler yıkama, arıtma ve öğütme gibi çeşitli ön işlemlerden geçirilmektedir (Ozmak, 2010). Ön isslem sonrası oksijensiz ortamda 500$950{ }^{\circ} \mathrm{C}$ 'de termal karbonizasyon (piroliz) uygulanmaktadır (Menderez-Diaz vd., 2006). Bu aşamada, organik maddeden nem ve uçucu maddeler uzaklaşarak yapının karbon oranı 
artmakta, yüksek 1sı ile çapraz bağlar bağlanarak, gözenekli sert doku oluşmaktadır (Akyıldız, 2007). Karbonizasyon sonrasinda yine yüksek 1sı altında aktivasyon işlemi uygulanmaktadır. Uygulanan aktivasyon işlemi üretilecek aktif karbonun uygulama alanına göre kimyasal özelliklerini değiştireceğinden, fiziksel aktivasyon ve kimyasal aktivasyon olarak iki farklı yöntem uygulanabilmektedir (Ozmak, 2010). Fiziksel aktivasyonda genellikle su buharı veya $\mathrm{CO}_{2}$ gibi oksitleyici ajanla aktivasyon gerçekleştirilirken, kimyasal aktivasyonda; $\mathrm{ZnCl}_{2}, \mathrm{H}_{3} \mathrm{PO}_{4}, \mathrm{AlCl}_{3}$, $\mathrm{MgCl}_{2}, \mathrm{KOH}, \mathrm{NaOH}$ gibi kimyasal aktifleştirici ajanlar kullanilarak, hammaddenin belirli sicaklıklarda bozundurulması sağlanmaktadır (Menderez-Diaz vd., 2006; Akyıldız, 2007; Ozmak, 2010; Türkmen, 2015). Aktivasyon aşamasında karbonun yanma reaksiyonu sonucu ortaya çıkan uçucu maddeler oksijenle birleşerek ortamdan uzaklaşmakta, böylece gözenek hacmi ve yüzey alanı artmaktadır (Dermanlı, 2006). Aktivasyon sonrası kimyasal madde kullanımına bağlı safsızlıkların giderimi için genellikle deiyonize su ile yıkama ve ardından kurutma işlemi uygulanmaktadır. Üretilen aktif karbonlar uygulama alanına göre ögütülüp basınç altında şekil verilmektedir (Menderez-Diaz vd., 2006).

\section{Aktif Karbonların Rejenerasyonu}

Çeşitli uygulamalarla organik ve inorganik bileşikler, toksik metal iyonları, ağır metaller, boya, pestisit ve ilaç gibi kontaminantlarla doygunluğa erişen aktif karbonların tekrar kullanılabilmesi ve adsorplanan maddenin konsantre edilmesi için rejenerasyon yöntemleri uygulanmaktadır. Bu yöntemlerin en yaygın olanlar1: buhar rejenerasyon, termal rejenerasyon, kimyasal rejenerasyon, sulu oksidasyon rejenerasyon, biyo-rejenerasyon, elektrokimyasal rejenerasyon, hidrotermal uygulama ve mikrodalga ile rejenerasyondur (Gamal vd., 2018). Buhar rejenerasyonunda, buhar sayesinde kontaminantların hizlı desorpsiyonu ve adsorbat uzaklaştırılması sağlanmaktadır (Gamal vd, 2018). Termal rejenerasyon tambur firınlar, akışkan yataklı veya sabit firınlar sayesinde $105{ }^{\circ} \mathrm{C}$ 'de kurutulan yoğun reaktif kontaminantların, inert atmosfer altında oksitleyici bir gaz (su buharı veya $\mathrm{CO}_{2}$ ) ile pirolizini ve organik kirleticilerin gazlaştırılmasını içermektedir. Termal oksidasyon aktif karbonun adsorpsiyon kapasitesini ve mekanik gücünü de yıpratmaktadır. Kimyasal rejenerasyonda belirli asidik ve alkali kimyasal reaktifler adsorbanları reaktifliklerine göre çözmek veya ayrıştırmak için kullanılmaktadır. Kimyasal rejenerasyon tipik olarak sifir karbon yıpranmasina yol açmakta ve adsorpsiyon kapasitesinin geri kazanımını sağlamaktadır. Sulu oksidasyon rejenerasyonda toksik kirleticiler daha az toksik türler oluşturmak için sulu ortamlarda ayrıştırılmaktadır (Gamal vd., 2018). Elektrokimyasal rejenerasyonda yüksek sıcaklıklara çıkılmadan ve herhangi bir kimyasal ilavesi olmadan adsorbe edilen organik kirletici maddeler yerinde kırllirken, karbonun yapisal bütünlüğü ve özellikleri etkilenmemektedir. İşlemde uygulanan elektrik alanı, daha sonra elektrotların yüzeyine adsorbe olan kutuplu iyonları ve molekülleri elektrolitten uzaklaştırmaktadır. Anottaki elektrokimyasal oksidasyon kirleticileri karbondioksit ve suya dönüşmektedir. Elektrolitik rejenerasyon organik maddelerin, boyaların ve çözünmüş ilaçların aktif karbondan desorpsiyonu için uygulanan yöntemdir (Alvarez-Pugliese vd., 2019). Biyorejenerasyonda karbonun kapasitesini ve yüzeyini yenilemek için mikroorganizmalar kullanılmakta olup, fenolik organikler ve organik maddelerin desorpsiyonu için yaygın olarak uygulanmaktadır. Biyo-rejenerasyon kirletici biyo-bozunurluğu, kirletici-karbon etkileşiminin gücü ve aktif karbon proses konfigürasyonunun fiziko-kimyasal özellikleri gibi faktörlere bağlıdır. Aktif karbonun biyo-rejenerasyon ile desorpsiyon mekanizmaları konsantrasyon gradyanı, ekzoenzim reaksiyonları, çözünmüş oksijen konsantrasyonu, mikroorganizma tipi, substrat-karbon temas süresi gibi parametrelere bağlıdır (Gamal vd., 2018). Hidrotermal uygulama ise ilaç ve pestisit gibi organik kirleticilerin uzaklaştırılması ve ekstraksiyonları için uygun olan bir yöntemdir (Sühnholz vd., 2018). Mikrodalga rejenerasyonunda kullanılmış aktif karbonların mikrodalgalara (MW) maruz kalması ile termal olarak aktifleşen reaksiyon mekanizmaları desorpsiyon sağlamaktadır. Özellikle fenolik bileşiklerin desorpsiyonunda uygulanan mikrodalga rejenerasyonu geleneksel rejenerasyon 
işlemlerine göre daha az enerji gerektirmekte ve harcanan karbonun adsorpsiyon kapasitesi açısından daha güvenli ve hızlı kazanım sağlanmaktadır (Yağmur, 2017).

\section{Gıda Atıklarından Aktif Karbon Üretimi}

Karbon içeriği yüksek, inorganik madde içeriği düşük, yüksek yoğunluklu, mekanik direnci yüksek, yeterli uçucu madde içeren maddelerden aktif karbon üretmek mümkündür (Ozmak, 2010). Tipik bir aktif karbon \%80-95 C, \%0.5 H, $\% 0.5 \mathrm{~N}, \% 1 \mathrm{~S}, \% 6-7 \mathrm{O}$ ve uçucu kül içermektedir
(Türkmen, 2015). Ancak kullanım alanına göre aktif karbonun istenen özellikleri değişeceğinden, elde edilecek olan son ürün özellikleri seçilecek olan hammaddeye bağlıdır. Yaygın olarak kullanılan hammaddeler gida atık kökenli olup, odun, biyokütle atıkları, zirai atıklar, gida sert çekirdekleri ve kabukları, gıda endüstrisi atıkları, kömür, linyit, turba gibi kolay bulunabilen ve düşük maliyetli atıklardır (Ozmak, 2010). Gıda kökenli üretilen aktif karbonlar ve kullanım alanları Çizelge 1'de görülmektedir.

Çizelge 1. Gıda atıklarından üretilen aktif karbonların endüstriyel uygulama alanları

\begin{tabular}{|c|c|c|c|c|c|c|c|}
\hline Köken & $\begin{array}{c}\text { Aktivasyon } \\
\text { Ajanı }\end{array}$ & $\begin{array}{l}\text { Karbonizasyon } \\
\text { sicaklığ1 }\left({ }^{\circ} \mathrm{C}\right)\end{array}$ & $\begin{array}{l}\text { Fiziksel } \\
\text { Form }\end{array}$ & $\begin{array}{l}\text { Yüzey } \\
\text { Alani } \\
(\mathrm{BET}) \\
\mathrm{m}^{2} / \mathrm{g}\end{array}$ & $\begin{array}{l}\text { Adsorpsiyon } \\
\text { Kapasitesi mg/g }\end{array}$ & $\begin{array}{l}\text { Uygulama } \\
\text { alanları }\end{array}$ & Kaynak \\
\hline $\begin{array}{l}\text { Zeytin } \\
\text { çekirdeği }\end{array}$ & $\begin{array}{c}\mathrm{H}_{3} \mathrm{PO}_{4} \\
\text { (fosforik asit) }\end{array}$ & $200-700$ & Toz & 1133 & - & $\begin{array}{l}\text {-Çözücü geri } \\
\text { kazanımı } \\
\text {-Endüstriyel } \\
\text { koku giderme }\end{array}$ & $\begin{array}{l}\text { Aky1ld1z } \\
\text { (2007). }\end{array}$ \\
\hline $\begin{array}{l}\text { Muz } \\
\text { gövdesi } \\
\text { atıklar1 }\end{array}$ & $\begin{array}{c}\mathrm{H}_{3} \mathrm{PO}_{4} \\
\text { (fosforik asit) }\end{array}$ & 845 & Toz & 1173,16 & 166,51 -199,87 & $\begin{array}{l}\text { Sentetik boyadan } \\
\text { metilen mavisi } \\
\text { giderimi }\end{array}$ & $\begin{array}{l}\text { Danish vd., } \\
\text { (2018). }\end{array}$ \\
\hline Nişasta & $\mathrm{Na}_{2} \mathrm{CO}_{3}$ & $300-400$ & Toz & 161 & $66,2-36,65$ & $\begin{array}{l}\text { Hizlı pestisit } \\
\text { adsorpsiyonu }\end{array}$ & $\begin{array}{ll}\text { Suo vd., } & \text { vd } \\
(2019) . & \\
\end{array}$ \\
\hline $\begin{array}{l}\text { Meyve } \\
\text { at1klar1 } \\
\end{array}$ & $\begin{array}{c}\mathrm{ZnCl} 2 \text { ve } \\
\mathrm{H}_{2} \mathrm{SO}_{4} \\
\end{array}$ & 450 & Toz & 600 & 194,7 & Zn adsorpsiyonu & $\begin{array}{l}\text { Türkmen } \\
(2015) .\end{array}$ \\
\hline $\begin{array}{l}\text { Kestane } \\
\text { kabuğu }\end{array}$ & İnert $\mathrm{N}_{2}$ & 900 & Lif & 280,42 & 333,3 & $\begin{array}{l}\text { Metilen mavisi } \\
\text { giderimi }\end{array}$ & $\begin{array}{l}\text { İzkeçeli } \\
(2010)\end{array}$ \\
\hline $\begin{array}{l}\text { Kiraz } \\
\text { çekirdeği }\end{array}$ & $\begin{array}{c}\mathrm{K}_{2} \mathrm{CO}_{3} \\
\text { (Potasyum } \\
\text { Karbonat) }\end{array}$ & 850 & Granül & - & 87,72 & $\begin{array}{l}\text { - Sulu çözeltiden } \\
\text { boyar madde } \\
\text { (metilen mavisi) } \\
\text { giderimi } \\
\text { - Atık su arıtımı }\end{array}$ & $\begin{array}{l}\text { Gerçel } \\
\text { (2015). }\end{array}$ \\
\hline $\begin{array}{l}\text { Çay } \\
\text { atıkları }\end{array}$ & $\begin{array}{c}\mathrm{H}_{3} \mathrm{PO}_{4} \\
\text { (fosforik asit) } \\
\mathrm{K}_{2} \mathrm{CO}_{3} \\
\text { (Potasyum } \\
\text { Karbonat) }\end{array}$ & 450 & Toz & $558-701$ & $270-84$ & $\begin{array}{l}\text { Metilen mavisi } \\
\text { ve fenol } \\
\text { adsorpsiyonu }\end{array}$ & $\begin{array}{l}\text { Ozmak } \\
(2010) .\end{array}$ \\
\hline $\begin{array}{l}\text { Balik } \\
\text { at1kları }\end{array}$ & İnert $\mathrm{N}_{2}$ & $350-800$ & Toz & $125-401$ & $112-421$ & $\begin{array}{l}\text { İyot } \\
\text { adsorpsiyonu } \\
\text { atık geri } \\
\text { dönüşümü } \\
\end{array}$ & $\begin{array}{l}\text { Fadhil } \\
\text { (2017). }\end{array}$ \\
\hline $\begin{array}{l}\text { Misır } \\
\text { koçanı }\end{array}$ & $\begin{array}{c}\mathrm{H}_{2} \mathrm{O}_{2} \\
\text { ( Hidrojen } \\
\text { Peroksit) }\end{array}$ & 450 & Toz & $500-1500$ & 60 & $\begin{array}{l}\text { Endüstriyel } \\
\text { atıklardan Ağır } \\
\text { metal } \\
\text { adsorpsiyonu }\end{array}$ & $\begin{array}{l}\text { Christica,v } \\
\text { d., (2018). }\end{array}$ \\
\hline
\end{tabular}




\begin{abstract}
Aktif Karbonun Gıda Endüstrisinde Kullanım Alanları

Gıda endüstrisinde uygulama alanı olarak iki tür aktif karbon mevcuttur: 1-G1da katk1 maddesi/ilaç olarak kullanılan ve oral olarak tüketilebilen medikal aktif karbon, 2-Saflaştırna ajanı olarak istenmeyen bileşikleri adsorblandıktan sonra ortamdan uzaklaştırılan aktif karbon.
\end{abstract}

Oral olarak tüketilebilen aktif karbonların, gidalara renk verme ve vücuttaki toksin maddeleri adsorplama amaçlı E153 kodlu gıda katkı maddesi olarak (CAS no: 7440-44-0), toz veya granül şeklinde ticari satısı mevcuttur. Gıda endüstrisinde direkt insan tüketimine izin verilen aktif karbonlar, doğal hammaddelerden ve üretim aşamalarında güçlü olarak saflaştırma uygulamalarından geçirilerek, steril olarak üretilmektedir. Üretilen aktif karbonun bazı saflık kriterlerini ve adsorpsiyon gücünü karşılaması gerekmektedir. $\mathrm{Bu}$ kriterler Birleşmiş Milletler Gida ve Tarım Örgütü (FAO) tarafindan yayınlanan "Aktif Karbon Monografi"nda ve Avrupa Farmakopisindeki (European Pharmacopeia) medikal aktif karbon bildirisinde (FAO-JECFA) yayınlanmışıtır (Anonymous, 2010).

Gıda endüstrisinde aktif karbon kullanımı 1794'de İngiltere'de şeker ağartma işlemi ile başlamıştır. Aktif karbonun türü, uygulama alanına göre değişmektedir. Şeker, şurup ve pekmez üretiminde istenmeyen, enzimatik olmayan esmerleşme reaksiyonu ürünleri olan melanin, melanoid, karamel ve heksoz alkali bozunma ürünlerinin neden olduğu koyu renklerinin uzaklaştırılması (ağartma işlemi) için aktif karbonun yüksek renk adsorplama özelliğinden yararlanılmaktadır (Ozsoy, 2010). Hurma şurubundan koyu renk uzaklaştırmak için kullanılan ağaç bazlı toz ticari aktif karbon ile 60 ${ }^{\circ}$ C'de \%95 renk adsorpsiyonu başarılmıştır (Nasehi vd., 2012). Pancar kökü pekmezinden istenmeyen renk uzaklaştırması çalışmasında $\mathrm{TiO}_{2}$ tübüler seramik membran üzerine emdirilmiş yüksek saflıkta toz ticari aktif karbon üzerinden çapraz akışlı ultrafiltrasyon uygulaması ile 25 ${ }^{\circ}$ C'de \% 98 renk adsorpsiyonu sağlanmıştır (Bernal vd., 2016). Şeker pancarı küspesi bazlı üretilen farklı özelliklerde (yüzey alanları, gözenek hacimleri, kütle yoğunlukları ve kül içeriği) aktif karbon kullanılarak şeker şurubu, melas ve iyot renk giderimi performansları incelenmiş, renk giderimi kapasitesinin fiziksel ve kimyasal özellikler ile yakından ilişkili olduğu görülmüştür (Mudoga vd., 2008).

İçme suyu arıtımında aktif karbon kullanımının, koku ve tat kontrolünde ekonomik ve verimli bir uygulama olarak kullanılabileceği bildirilmektedir. İçme suyunda bulunan siyanobakterilerin (örneğin, Anabaena aphanizomenon, Lyngbya, microcystis, Oscillatoria, Phormidium) ve aktinomisetlerin (örneğin, Nocardia, Streptomyces, Actinomadura, Micromonospora) ötrofik koşullar altındaki içme suyuna istenmeyen koku ve tat veren metabolitleri geosmin (toprak kokusu) ve 2Metilizoborneol (küflü koku)'ün aktif karbon ile uzaklaştırılma çalışmaları mevcuttur (Srinivasan, 2011). Ticari granül aktif karbon başlıklı filtreler kullanılarak, 2-12 aylık içme suyu filtreleme işleminden sonra 2-MIB'nin ortalama $\% 60^{\prime}$ 'nın ve geosminin \%80'inin sudan arıtılması başarılmışıtır (Ridal vd., 2001). Kimyasal ve buhar aktivasyonları ile kömür ve ağaç bazlı granül aktif karbonların geosmin ve 2-MIB uzaklaştırma performanslarının karşılaştırıldığ1 bir diğer çalışmada kimyasal aktivasyonlu kömür bazlı, düşük kül içerikli aktif karbonun $5,5 \mathrm{mg} / \mathrm{L}$ miktarının $15 \mathrm{dk}$ süresince $\% 85$ geosmin, $\% 68$ 2-MIB adsorplama kapasitesinin olduğu görülmüştür (Cullum, 2007). Aktif karbon kullanılarak içme suyundan çeşitli mikroorganizmalar, klor ve yan ürünleri, organik kimyasallar (fenol, metilen klorür, trikloretilen, benzen, klorobenzenler, karbon tetraklorür, pikrik asit ve salisilik asit gibi) petrol ve yan ürünleri gibi uçucu organik kimyasalların uzaklaştırılması mümkündür (Lemley vd., 1995; Qadeer, 2002).

Şarap, sirke ve alkollü içecek endüstrisinde, fazla tanenin, istenmeyen renk, koku unsurlarının, tortu, bulanıklık oluşturan maddelerin uzaklaştırılması ve aroma izolasyonu amaçlı aktif karbonun kullanıldığı bazı çalışmalar mevcuttur (Lisanti vd., 2017). Şarapta bulunan mikrobiyal kökenli geosmin (toprak kokusu) ve 1-octen-3- 
one (güçlü metalik mantar benzeri koku) gibi istenmeyen kokuların giderimi için aktif karbonlar ile çalışılmış, geosmin konsantrasyonu (40 $\mathrm{g} / \mathrm{hl}$ aktif karbon) $\% 92$ oraninda ve 1-okten-3-on konsantrasyonunu (40 g/hl aktif karbon) \%73 oranında azaltılmıştır (Behr vd., 2013). Aspergillus carbonarius mantar türlerinin ürettiği mikotoksin olan okratoksin, farklı aktifleştirme ajanları ile aktive edilmiş aktif karbonlar sayesinde şaraptan \%98'e kadar uzaklaştırılmıştır (Quintela vd., 2013). Alkollü içecek endüstrisinde özellikle bira ve şarap ürünlerinin fermantasyonu tamamlandıktan sonra, bekleme fiçılarının mikro gözeneklerinde Brettanomyces gibi bozulmaya neden olan mayaların gelişimini inhibe etme, etilfenol oluşumunu destekleyen koşulları önleme ve Brettanomyces metabolitleri ile kontamine olmuş içeceklerden 4-etilfenol ve 4-ethylguaiacol lezzetini azaltma amaçlı aktif karbonlar gida katk1 maddesi olarak kullanılmaktadır (Tubia vd., 2018). Beyaz ve pembe şarap sirkelerinde toz aktif karbon ile renk giderimi çalışmasında iyon değiştirici reçine ve aktif karbon karşılaştırılmıştır. Bu çalışmada iyon değiştirici reçine \%69-72 renk adsorplama performansı gösterirken aktif karbon \% 94-98 adsorplama performans1 göstermiştir (Achaerandio vd., 2002).

Klimakterik meyve ve sebzelerde (muz, avokado, domates vb) olgunlaşma sürecini başlatan ve doğal olarak salgılanan etilen gazı, raf ömrünü uzatmak için aktif karbonlar ile kontrol edilebilmektedir. Pd destekli aktif karbon veya bromlaştırılmış kömür, etilen gazı süpürücü etkisi yönünden $\quad 0-1000 \quad \mathrm{mg}$ dozlarda avakadoya uygulanarak çalışılmış, aktif karbon eklenen ürünlerin renginde $12{ }^{\circ} C^{\prime}$ de 3 gün süresince önemli bir değişiklik olmadığı saptanmıştır (Smith vd., 2009; Dhall, 2013).

Gıdalardan besinsel olmayan maddelerin uzaklaştırılması, farmasötik ajanlar, bakteri ve toksin uzaklaştırılması gibi detoksifikasyon uygulamaları için de aktif karbonlar kullanılmaktadır. Ksilozun Candida guilliermondii mayası indirgenmesiyle gida endüstrisinde tatlandırıcı olarak kullanılan ksilitol'e (5 karbonlu şeker alkolü) biyolojik dönüşümü için kullanılan konsantre pirinç samanı hemiselülozik hidrolizatının detoksifikasyonunda aktif karbon kullanılmış olup, $40 \mathrm{~g} / \mathrm{g}$ dozda hidrolizat/kömür oran1, asetik asit, terpen ve tanin gibi fenolik bileşiklerin \%27'sinin inhibisyonu sağlanmıştır (Mussatto, 2001). Gidalarda yaygin olarak bulunabilen, diyare, hemorajik kolit, akut immün trombositopenik veba gibi hastalıklara yol açan Escherichia coli 0157:H7 suşlarının ve toksin maddesi olan verotoksin 2'nin $5 \mathrm{mg}$ ticari yenebilir aktif karbon yüzeyine bağlanma kapasitesi araştırılmıştır. Besiyeri ortamında $37^{\circ} \mathrm{C}$ 'de $30 \mathrm{dk}$ aktif karbonla yavaş karıştırma ile inkübasyonu sonucu bakteri sayisinin $7,72 \pm 0,25 \times 10^{6}$ dan $3,63 \pm 0,36 \times 10^{3}$ 'a azaldığ 1 ve verotoksin uzaklaştırılmasında aktif karbonun başarılı absorbant özelliği gösterdiği görülmüştür (Naka vd., 2000).

Gıda endüstrisinde aktif karbonların bir diğer kullanım alanı ise saflaştırma ve geri kazanım prosesleridir. Fonksiyonel gida maddesi olarak çeşitli içecekler, kurabiye ve yoğurt gibi gıdalarda yaygin bir şekilde kullanılan fruktooligosakkaritlerin (FOS) saflaştırılması, glukoz, fruktoz, sakkaroz ve fruktooligosakkarit içeren bir şeker karışımı içinden sabit yataklı kolonda aktif karbon kullanılarak \%80 saflıkta \%97,8 geri kazanımı başarılmıştır. Ticari aktif karbonlar ile $5 \mathrm{mg}$ aktif karbon/100 ml şeker karışımı saflaştırılmasında, $120 \mathrm{dk}$ sonra dengeye gelen çözeltide adsorbe edilen maksimum FOS miktar1 0,92 g FOS/g aktif karbon olarak belirlenmiştir (Nobre vd., 2012; Kuhn vd., 2010). Bitki hücre duvarlarında bol miktarda bulunan fenolik bir fitokimyasal olan ferulik asitin yüksek saflıkta elde edilmesi, şeker kamış küspesinden ticari granül ve toz aktif karbon kullanilarak araştırılmış, adsorpsiyon kapasiteleri toz ve granül aktif karbon için sırasıyla 280 ve $210.5 \mathrm{mg} / \mathrm{g}$ olarak bulunmuştur (Ou vd., 2007). Turunçgil meyve atıklarından elde edilen pektin tozu ve Aspergillus ibericus mantar1 kullanilarak elde edilen saf pektinaz enzimi nano gözenekli aktif karbon yüzeyine kaplanarak fonksiyonel hale getirilmiş ve dolgulu yatak reaktör içine doldurularak atık sudan \%94 oranında pektin saflaştırılması işlemi başarılmışıı (Mahesh vd., 2016). Enzim saflaştırması gibi uygulamalarda da alternatif bir yol olarak aktif karbon kullanılmaktadır. 
Thermomyces lanuginosus lipaz model enziminin yüksek gözenekli aktif karbon-silika kompozit malzemesi hazırlanarak hidrofobik aktif karbon yüzeyine güçlü bir şekilde arayüzey aktivasyonlu kovalent bağlanması incelenmiş, adsorpsiyon aktivitesi 8,6 U/g kuru malzeme ve kalan kovalent immobilizasyon $31 \mathrm{U} / \mathrm{g}$ kuru malzeme olarak bulunmuştur. Kovalent tutunma aktivitesi pnitrofenil palmitat substratları kullanilarak 45 $\mathrm{mg} / \mathrm{g}$ karbon materyali başına en yüksek lipaz aktivitesi $10 \mathrm{U} / \mathrm{g}$ kuru malzeme şeklinde bulunmuştur (Reichardt, vd. 2018). Aktif karbon kullanılarak, kızartma yağından benzo(a)piren gibi kanserojen polisiklik hidrokarbonları ve poliklorin bifenil gibi dioksin uzaklaştırma işlemleri gerçekleştirilmiştir. $\mathrm{Bu}$ amaçla, aktif karbon yoğunluklu bentonit ve selit karışımlı adsorbanlar kullanılarak, 36 saat kullanılmış kızartma yağ1 vakum altında filtrelenmiş ve aktif karbon sayesinde yağ rengi daha aç1k hale getirilmiştir. Serbest yağ asidi $\% 44,3$ ve peroksit değeri $\% 50,2$ oranında azalmıştır (Udomkun vd., 2018). Poliklorlu dibenzo-p-dioksinler, dibenzofuranlar (PCDD / F) ve dioksin benzeri poliklorin bifenil (PCB) kirleticileri ile kontamine olan morina balığ karaciğer yağında \%0,5 aktif karbon kullanılarak $\% 80$ oranında PCB kirleticilerinin uzaklaştırılması başarılmıştır (Maes vd., 2005). Polisiklik hidrokarbonlarin (fenantren, antrasen, fluoren, piren, benzo(a)piren, krisen, benzo(b)fluoranten, benzo(k)fluornten, benzo(a)antrasen uzaklaştrilmasında \%2 aktif karbon ilavesi sonucu topraktan \%99, sulu ortamdan \%95,6-100 uzaklaştırma verimi ile aktif karbon, kitosan, leonardit, silika gibi endüstriyel adsorbanlara kiyasla daha etkin bulunmuştur (Lamichhane vd., 2016).

Tarımsal ürünlerden ve içme suyundan pestisitlerin hızlı bir şekilde uzaklaştırılması için mezo-gözenekli veya granül aktif karbonlar kullanılmaktadir. Pestisitlerin aktif karbona adsorpsiyon afiniteleri; adsorbat hidrofobikliği, fonksiyonel grubun karakteri (polarite, iyonik yap1, fonksiyonel gruplar ve çözünürlük) ve moleküler yapıya bağlıdır. Elektrostatik ve Van der Waals kuvvetleri, H-bağlayıc1, dipol-dipol etkileşimleri, iyon değişimi, kovalent bağ aktif karbondaki organik bileşiklerin adsorpsiyonundan sorumludur (Derylo-Marczewska vd., 2019). İçme suyundan her biri $0,5 \mathrm{mg} / \mathrm{ml}$ oraninda bulunan Atrazine, Pymetrozine, Acetamiprid, Diuron, Thiacloprid, Imizalil, Pyraclostrobin, Difenoconazole, Trifloxystrobin, Chlorantraniliprole gibi 11 farklı pestisit $10 \mathrm{ml}$ 'lik çözeltilerden $50 \mathrm{mg}$ ticari aktif karbon kullanılarak \%85-\% 98 adsorplama kapasiteleri ile uzaklaştırllmıştır (Suo vd., 2019). Diazinon pestisitin sudan uzaklaştırılmasında ceviz kabuğu bazlı aktif karbon kullanılarak, kesikli ve sabit yataklı adsorpsiyon sistemde çalışılmış ve 1-40 $\mathrm{mg} / \mathrm{L}$ pestisit içeren çözeltiden en yüksek seviyede uzaklaştırma için yatak kapasitesi 34,98 $\mathrm{mg} / \mathrm{g}$ doz aktif karbon olarak belirlenmiştir (Bayat vd., 2018). Organofosfat insektisit olan Malathion'un içme suyundan granüler aktif karbon ile uzaklaştırılması çalışılmış ve pestisin konsantrasyon seviyesinin 1,75-1,80 $\mu \mathrm{g} / \mathrm{L}$ 'ye kadar düşürülmesi 909,1 mg/g dozda başarılmışır (Jusoh vd., 2011).

\section{Güncel Uygulamalar}

Aktif karbonların gıda endüstrisi alanında yeni uygulama alanlar1; anaerobik sindirim proseslerinde uçucu yağ asitlerini tutma, amonyak azotu oranı kontrolü ile metan gazı üretim performansını arttırma, gıda katk1 maddelerini saflaştırma, modifiye atmosfer uygulamalarında $\mathrm{CO}_{2}$ gazı kontrolü, yeni nesil antimikrobiyal ajan, uçucu organik bileşiklerin uzaklaştırılması, aroma bileşenleri geri kazanımı, aktif karbon elektrokimyasal sensörler (EDCL elektrot) ve elektromanyetik aktif karbonlarla verimli ayırma prosesleri şeklinde sıralanmaktadır.

Gıda atıklarından yenilenebilir enerji (biyoyakıt) üretiminde, anaerobik sindirim proseslerinde reaktörün uçucu yağ asitleri aşırı yüklenmesi ve yüksek protein içeriği ile mikroorganizmalar için toksik olan artan amonyak azotu proses verimini düşürmektedir, dolayısıyla bu bileşenlerin reaktör ortamından uzaklaştırılması için aktif karbon uygulamalarindan yararlanilmaktadır (CapsonTojo vd., 2018). Konuyla ilgili olarak ayrıca, anaerobik sindirim ürünü sıvı fazının renk giderimi, mikroorganizma etkinliği ve metan gazı üretim verimi aktif karbonlar ile arttırılmıştır (Farooq vd., 2017). Ardış1k seri reaktörlerin 
anaerobik sindirim performansına (uçucu yağ asidi tüketimine) yardımcı olarak granül aktif karbon ile $\mathrm{Co}, \mathrm{Mo}, \mathrm{Ni}$ ve Fe gibi iz elementlerin birlikte kullanımı, biyokütle uyumunu, asetik asit tüketimini ve metan üretimini arttırmışır (Capson-Tojo vd., 2018).

Gida endüstrisinde monosodyum glutamat (MSG), glutamik asit ve hidrolize edilmiş bitkisel proteinler (HVP'ler) gibi yaygın şekilde kullanılan katkı maddelerinin saflaştırma çalışmalarında da aktif karbon kullanılmaktadır (Kobayashi vd., 2018; Wang vd., 2017). Yüksek mikro gözeneklere sahip toz aktif karbon gida muhafazasında modifiye atmosfer uygulamalarında kullanılmaktadır. Yerel bir hurmanın (Phoenix dactylifera) tohumlarından elde edilen aktif karbon ile en yüksek $\mathrm{CO}_{2}$ adsorplama kapasitesi $20^{\circ} \mathrm{C}$ 'de $141,14 \mathrm{mg} \quad \mathrm{CO}_{2} \quad \mathrm{~g}$ aktif karbon olarak bulunmuştur (Ogungbenro vd.,2018).

Biyolojik atıktan aktif karbon nanopartikülleri ile herhangi bir yan etkisi olmadan patojen kaynaklı hastalıkları etkin bir şekilde yok edebilen yeni nesil antimikrobiyal ajanlar üretilmektedir. Aktif karbon nanopartikülü, gram negatif mikroorganizmalar ve karbon yüzeyi arasında elektrostatik itme kurarak mikroorganizmay1 uzaklaştırabilme oranını artırmaktadır. Mikroorganizma, güçlü Vander Waals kuvvetleri vasitasıyla karbon partiküllerine yapışır, mikroorganizma gram pozitif ise, o zaman karbon yüzeyindeki pozitif yükün modifikasyonu yapılabilir. Hindistan cevizi kabuğu $\left(876,2 \mathrm{~m}^{2} / \mathrm{g}\right.$ yüzey alanı) ve şeker kamışı küspesi aktif karbon nanopartiküllerinin Escherichia coli 'ye (107 $\mathrm{CFU} / \mathrm{mL}$ ) karşı 1-6 saat temas süresi ile tam hücre ölümü, pirinç kabuğu küspesi aktif karbon nanopartiküllerinin ( $\mathrm{pH}: 7$ ve oda sicakliğında) Bacillus species'e $\left(3,2 \times 10^{7} \mathrm{CFU} / \mathrm{mL}\right)$ karşı, hurma tohumlarından elde edilen aktif karbon nanopartiküllerin Pseudomonas aeruginosa, Eschericbia coli, Staphylococcus aureus, Staphylococcus epidermidis ve Candida albicans mikroorganizmalarına karşı yüksek antimikrobiyal etkinlik gösterdiği bildirilmektedir (Lakshmi vd., 2018).
Gıda proseslerinde atık maddelerle birlikte kaybedilen bazı bileşiklerin ve minerallerin $(\mathrm{Pb}$, $\mathrm{Cu}$ gibi) geri kazanımı da aktif karbon kullanılarak gerçekleştirilebilmektedir. Süt proteinleri ile kaplanmış aktif karbon (10-70 g/L dozda 20-40 ${ }^{\circ} \mathrm{C}$ ) ile zeytin karasuyundan polifenollerin (gallik asit, hidroksitirosol, 3,4 dihidroksibenzoik asit, tirosol, kafeik asit, kumarik asit) hizlı geri kazanımının, geleneksel ekstraksiyon yöntemine göre $\% 80$ daha verimli olduğu bildirilmektedir (Yangui, 2018).

Gıda üretim aşamalarında, fermentasyon, pişirme, buharlaştırıcı yoğuşma, 1sıtma, kurutma işlemlerinde salınan hidrokarbonlar, halkalı yapılar, aromatikler, genellikle gıdalarda kötü koku-tat oluşturan, toksik, mutajenik ve karsinojenik etki gösteren uçucu organik bileşiklerdir. Ayrıca temizlik, dezenfeksiyon adımlarında da klorlu bileşikler ve diğer $\mathrm{H}_{2} \mathrm{~S}, \mathrm{NO}_{\mathrm{x}}$ gibi kirlilik yaratan gazların ortamdan uzaklaştırılmaları gerekmektedir. Uçucu organik bileşiklerin ortamdan uzaklaştırılması için aktif karbonlar daha ekonomik ve tekrar kullanılabilir adsorbanlardır (Olgun vd., 2017). Gaz kromatografisi cihazlarının uçucu bileşikleri ayırmadaki temel çalışma prensipleri de aktif karbonlar yardımıyla gerçekleşmektedir (Diaz vd., 2005). Gıda üretim sektörlerinde; firınlama, bitkisel yağ çıarma, katı yağ işleme, kahve üretimi, şeker pancarı işleme, bira, şarap ve alkol üretimi gibi proseslerde oluşan, metil etil keton, etanol, amonyak, $\mathrm{H}_{2} \mathrm{~S}$ ve dimetil sülfit gibi uçucu organik bileşiklerin ortamdan uzaklaştırılmasında 10-10000 ppm aralı̆̆ında aktif karbon kullanilmaktadır (Preis vd., 2013).

Gidalarda antioksidan etki, renk ve tat gibi özelliklerden sorumlu olan doğal polifenolik bileşiklerin saflaştırılması ve geri kazanımında, yüksek seçicilik, yenilenebilirlik ve uygun maliyeti ile aktif karbon adsorpsiyonu uygulanmaktadır. Yapılan bir çalışmada, kafeik asit, kateşol, gallik asit, p-hidroksibenzoik asit, lignin, limonin, melanoidin, tannik asit, tannin, tirosol, vanilik asit, vanilin gibi bazı saf fenolik bileşikler 0,39-1971 $\mathrm{mg} / \mathrm{g}$ adsorpsiyon kapasitede geri kazanılabilmiştir (Soto vd., 2011). Diğer bir çalısmada ise hindistan cevizi kabuğu hammaddeli 
aktif karbon kullanılarak kahve aroma bileşiği olan benzaldehitin yüksek oranda geri kazanımı başarılmıştır (Saffarionpour, 2017).

Gıda içinde herhangi bir maddenin konsantrasyonunun belirlenmesinde, numune ön ekstraksiyonu, pahalı kimyasal kullanımı ve zaman almas1 gibi kistlamalar, aktif karbonla elektrokimyasal sensörlerin (EDCL elektrot) geliştirilmesini tetiklemiştir. Bu amaçla yürütülen bir çalışmada, şeftali çekirdeği bazlı aktif karbon ile basit, ekonomik ve hassas olarak kafein $(1,3$, 7-trimethylpurine-2,6-dione) tespiti yapılmış ve elektrokimyasal sensör olarak kafeinli içeceklerde (kolalı içecekler gibi) uygulanabilirliği incelenmiştir. Tespit limitleri 2,85 $\times 10^{-5}-1,60 \times$ $10^{-5} \mathrm{M}$ olarak hesaplanmış ve gerçek elektrotların test değerlerine yakın kafein konsantrasyonları elde edilmiştir (Arroyo-Gómez, vd. 2018). Bir diğer çalışmada, atık polietilen fitalat (PET) şişelerinden üretilen $\mathrm{KOH}$ aktivasyonlu cams1 aktif karbon elektrotların, mükemmel elektrokatalitik aktiviteleriyle, karbofuran (2,2dimethyl-2,3-dihydro-7-benzofuranyl Nmethylcarbamate) pestisitini tespit performans1 çalıșılmıştır. Karbofuran-fenolü (karbofuran hidrolizi ile oluşur) $0,03 \mu \mathrm{M}$ konsantrasyonundaki gibi düşük limitlerde bile $\% 3,51^{\prime}$ lik standart sapma ile tespit eden ve $0,11 \mu \mathrm{A} / \mathrm{Mcm}^{2}$ duyarlilikta ölçüm yapan elektrotun ölçüm tekrarlanabilirliği kanıtlanmıştır (Ayyalusamy vd., 2018).

Manyetik nano ve mikro partiküller dış manyetik alana verdiği farklı yanıtlarla, maddelerin seçici ayrilmas1, hedeflenmesi ve lokalizasyonunu sağlamaktadır. Aktif karbon parçacıklarının, demir oksitler manyetit, maghemit veya farklı ferrit türleri ile hidrotermal reaksiyonlu yüzey modifikasyonu, aktif karbona yeni bir manyetik özellik kazandırmaktadır. Manyetik aktif karbonlar kimyasal çöktürme, 1sıl işlem ve enkapsülasyon işlemlerinde alternatif uygulama imkanı sunmaktadır (Safarik vd., 2012). Yapılan bir çalışmada, son kullanma tarihi geçmiş içeceklerin karbonhidratlarının (fruktoz, glukoz, sükroz) karbon kaynağı olarak kullanıldığı, $\mathrm{FeCl}_{3}$, $\mathrm{FeCl}_{2}$, ve üre katalizörlü hidrotermal reaksiyon ile üretilen manyetik karbonlar $\mathrm{KOH}$ ile aktifleştirilmiş ve ardından suda çözünür metilen mavisi boyasinın 404,73 $\mathrm{mg} / \mathrm{g}$ adsorpsiyon kapasitesi ile giderimi başarılmıştır (Liu, vd. 2019). Bir diğer çalışmada da triazin herbisitlerin süt ve pirinç gibi model gida örneklerinden absorpsiyonunu arttırmak için iyonik olmayan bir silikon yüzey üzerine manyetik modifiye aktif karbon kaplanmıs, triazin herbisitler ve adsorban arasındaki hidrofobik etkileşime bağlı olarak triazin herbisitlerin ayrilması gida numunelerinde \%81 oranında başarılmıştır (Mohd vd., 2019).

\section{SONUÇ}

Yüksek gözenekli yapıları ve geniş yüzey alanları ile mükemmel adsorban malzemeler olarak bilinen aktif karbonlar ayırma, saflaştırma, uzaklaştırma ve geri kazanım süreçleri için çok çeşitli alanlarda yaygın olarak kullanılmaktadır. Gıda endüstrisinde aktif karbon kullanımı, düşük maliyetli gida atıklarının aktif karbona dönüştürülmesi ile çevre dostu atık yönetimi politikası sağlaması, gıdalardan istenmeyen kirliliklerin giderimi, saf gida katk1 maddeleri üretimi, yeni nesil antimikrobiyal ajanlar ve elektrokimyasal sensörler ile gida analizi masraflarını azaltma, kolaylaştırma ve verimliliği artırma açısından avantajlar sunmaktadır. Elektromanyetik aktif karbonlar, ayırma ve saflaştırma verimleri oldukça başarılı olduğundan, gıda endüstrisinde gelecekte kullanım potansiyeli yüksek adsorbanlardır. Aktif karbonun yenilenebilme özelliği ile tekrar kullanılabilmesi uzun süreli kullanımı da mümkün kılmakta, bu durum uygulamalarda ekonomi sağlamaktadır.

\section{KAYNAKLAR}

Smith, A.W. J., Poulston, S., Rowsell, L., Terry, L. A., Anderson, J. A. (2009). A New PalladiumBased Ethylene Scavenger to Control EthyleneInduced Ripening of Climacteric Fruit. Platinum Met Rev., 53(3), 112-122. doi:10.1595/ $147106709 \times 462742$.

Anonymous (2002). Activated Carbon Processing, National Organic Standards Board Technical Advisory Panel Review Compiled by OMRI for the USDA National Organic Program, $1-23$.

Akylldı, H. (2007). $\mathrm{H}_{3} \mathrm{PO}_{4}$ Aktivasyonu ile zeytin çekirdeğinden aktif karbon üretimi, Yıldız Teknik 
Üniversitesi, Fen Bilimleri Enstitüsü, Kimya Mühendisliği Anabilim Dalı, Yüksek Lisans Tezi, İstanbul, Türkiye, $115 \mathrm{~s}$.

Ali, B. H., Alza'abi, M., Ramkumar, A., Al-Lawati, I., Waly, M. I., Beegam, S. (2014). The effect of activated charcoal on adenine-induced chronic renal failure in rats. Food Chem Toxicol, 65, 321-328. doi:10.1016/j.fct.2013.12.038.

Alvarez-Pugliese, C.E., Acuña-Bedoya,J., VivasGalarza,S., Prado-Arce,A., Marriaga-abrales,N. (2019). Electrolytic regeneration of granular activated carbon saturated with diclofenac using BDD anodes. Diamond \& Relat Mater, 93, 193199. doi:10.1016.

Ayyalusamy, S., $\quad$ Mishra, S., Suryanarayanan, V.(2018). Promising postconsumer PET-derived activated carbon electrode material for non-enzymatic electrochemical determination of carbofuran hydrolysate. Sci Rep, 8(13151), 1-9. doi:10.1038/s41598-018-31627-8.

Bayat, M., Alighardashi,A., Sadeghasadi,A. (2018). Fixed-bed column and batch reactors performance in removal of diazinon pesticide from aqueous solutions by using walnut shellmodified activated carbon. Environ Technol \& Innov, 12, 148-159. doi:10.1016/j.eti.2018.08.008.

Behr, M., Cocco, E., Lenouvel, A., Guignard, C., Evers, D. (2013). Technical Brief Earthy and Fresh Mushroom Off-Flavors in Wine: Optimized Remedial Treatments. Am J Enol Vitic, 64(4), 545-549. doi:10.5344/ajev.2013.13061.

Bernal, M., Ruiz M.O., Geanta, R.M. ,Benito,J.M., Escudero, I. (2016). Colour removal from beet molasses by ultrafiltration with activated charcoal. Chem Eng J, 283, 313-332. doi:10.1016/j.cej.2015.07.047.

Nobre, C., Teixeira, J.A., Rodriguez, L.R. (2012). Fructo-oligosaccharides purification from a fermentative broth using an activated charcoal column, New Biotechnol, 29(3), 395-401. doi:10.1016/j.nbt.2011.11.006.

Capson-Tojo, G., Moscoviz,R., Ruiz,D., SantaCatalina,G., Trably,E., Rouez, M., Crest,M., Steyer, J., Bernet, N. (2018). Addition of granular activated carbon and trace elements to favor volatile fatty acid consumption during anaerobic digestion of food waste, Bioresour Technol, 260, 157-168. doi:10.1016/j.biortech.2018.03.097.

Cullum, P. (2007). Evaluating the performance of different powdered activated carbons for taste and odour reduction. 32nd Annual Qld Water Industry Operations Workshop Walter Pierce Pavilion, Showgrounds Complex, Rockhampton, 38-44.

Christica, I.S., Muchlisya, M., Julia, R. (2018). Activated carbon utilization from corn cob (Zea mays) as a heavy metal adsorbent in industrial waste, Asian J Pharm Res and Dev, 6(5), 01-04.

Danish,M., Ahmad,T., Majeed,S., Ahmad, M., Ziyang, L., Pin, Z., Iqubal, S.M.S. (2018). Use of banana trunk waste as activated carbon in scavenging methylene blue dye: Kinetic, thermodynamic, and isotherm studies, Bioresour Tecbnol Rep, 3 ,127-137.

Dermanl1, Y. (2006). Gida fabrikasyon atıklarından aktif karbon üretimi ve soya yağını ağartma performansinın incelenmesi, İstanbul Teknik Üniversitesi, Fen Bilimleri Enstitüsü Gıda Mühendisliği Anabilim Dalı, Yüksek Lisans Tezi, İstanbul, Türkiye, $52 \mathrm{~s}$.

Derylo-Marczewska, A., Blachnio,M., Marczewski, A.W., Seczkowska,M. ,Tarasiuk,B. (2019). Phenoxyacid pesticide adsorption on activated carbon e Equilibrium and kinetics. Chemosphere, 214, 349-360. doi:10.1016/j.chemosphere.2018.09.088.

Dhall, R. K. (2013). Ethylene in Post-harvest Quality Management of Horticultural Crops: A Review. Res \& Rev: A Journal of Crop Sci Technol, 2(2), 9-24, ISSN: 2319-3395.

Diaz, E., Ordonez, S., Vega, A., Coca, J. (2005). Comparison of adsorption properties of a chemically activated and a steam-activated carbon, using inverse gas chromatography. Microporous and Mesoporous Mater, 82, 173-181. doi:10.1016/j.micromeso.2005.03.010.

Farooq, M., Bell,A., Almustapha,M.N., Andresen,J.M. (2017). Bio-methane from anaerobic digestion using activated carbon 
adsorption. Anaerobe, 46, 33-40. doi:10.1016/j.anaerobe.2017.05.003.

Anonymous (2010). World Health Organization,(WHO) Expert Committee on Food Additives, Compendium of food additive specifications: seventy-third [73rd] report, $W H O$ Tech Rep Ser, Rome, ISBN 978-92-5-106662-1, ISSN 1817-7077.

Fadhil, A.B., Ahmed,A.I., Salih, H.A. (2017). Production of liquid fuels and activated carbons from fish wate. Fuel, 187, 435-445.

Gamal, M. E., Mousa H.A., Naas, M.H., Zachharia, R., Judd,S. (2018). Bio-regeneration of activated carbon: A comprehensive review. Sep and Purif Technol, 197, 345-359. doi:10.1016/j.seppur.2018.01.015.

Gerçel, Ö., Seydioğlu, G. (2015). Kiraz çekirdeğinden granül aktif karbon üretimi. Anadolu Üniversitesi Bil ve Teknol Dergisi $A$ Uygulamal Bilimler ve Mühendislik, 16(2), 189-193, DOI: 10.18038/btd-a.93727.

Güneysu, S. (2003). Prina'nın aktif karbon olarak değerlendirilmesi. İstanbul Üniversitesi, Fen Bilimleri Enstitüsü, Çevre Mühendisliği Anabilim Dalı, Yüksek Lisans Tezi, İstanbul Türkiye, 69s.

Mudoga, H.L., Yücel, H., Kincal, N.S. (2008). Decolorization of sugar syrups using commercial and sugar beet pulp based activated carbons. Bioresour Technol, 99, 3528-3533. doi:10.1016/j.biortech.2007.07.058.

Achaerandio, I., Lopez, C.G.F., Ozmak, M. (2002). Continuous vinegar decolorization with exchange resins. J Food Eng, 51, 311-317.

İzkeçeli, M. (2010). Kestane kabuklarından sentetik aktif karbon hazırlanması ve metilen mavisi gideriminde kullanılması. Yıldız Teknik Üniversitesi, Fen Bilimleri Enstitüsü, Kimya Mühendisliği Anabilim Dalı, Yüksek Lisans Tezi, İstanbul, Türkiye, $73 \mathrm{~s}$.

Arroyo-Gómez, J.J., Villarroel.-Rocha, D., de Freitas-Araújo, K.C., Martínez-Huitle, C.A., Sapag, K. (2018). Applicability of activated carbon obtained from peach stone as an electrochemical sensor for detecting caffein. $J$ Electroanalytical
Chem,

822 ,

$171-176$

doi:10.1016/j.jelechem.2018.05.028.

Jusoh, A., Hartini,W.J.H., Ali,N., Endut,A. (2011). Study on the removal of pesticide in agricultural run off by granular activated carbon. Bioresour Technol, 102, 5312-5318. doi:10.1016/j.biortech.2010.12.074.

Kobayashi, K., Tanaka, M., Tanabe, S., Yatsukawa,Y.,Tanaka,M. (2018). Distinguishing glutamic acid in foodstuffs and monosodium glutamate used as seasoning by stable carbon and nitrogen isotope ratios. Heliyon, 4, 1-17. doi:10.1016/j.heliyon.2018.e00800.

Kuhn, R. C., Filho, F.M. (2010). Purification of fructooligosaccharides in an activated charcoal fixed bed column. New Biotechnol, 27(6), 863-869. doi:10.1016/j.nbt.2010.05.008.

Lamichhane, S., Krishna, K.C. B., Sarukkalige, R. (2016). Polycyclic aromatic hydrocarbons (PAHs) removal by sorption: A review. Chemosphere, 148, 336-353.

doi:10.1016/j.chemosphere.2016.01.036.

Lemley, A., Wagenet, L, Kneen, B. (1995). Activated Carbon Treatment of Drinking Water. Water Treat Notes, 1-6.

Lisanti, M. T., Gambuti, A., Genovese, A., Piombino, P.,Moio, L. (2017). Treatment by fining agents of red wine affected by phenolic offodour. Eur Food Res and Technol, 243(3), 501-510. doi:10.1007/s00217-016-2763-4.

Liu, Y., Huo,Z.,Song,Z.,Zhang,C., Ren,D.,Zhong, H.Jin,F. (2019). Preparing a magnetic activated carbon with expired beverage as carbon source and $\mathrm{KOH}$ as activator. J Taiwan Inst Chem Eng, 96, 575-587. doi:10.1016/j.jtice.2018.11.017.

Mahesh, M., Arivizhivendhan, K. V., Maharaja, P., Boopathy, R., Hamsavathani, V., Sekaran, G. (2016). Production, purification and immobilization of pectinase from Aspergillus ibericus onto functionalized nanoporous activated carbon (FNAC) and its application on treatment of pectin containing wastewater. $J$ Mol Catal B: Ensym, 133, 43-54. doi:10.1016/j.molcatb.2016.07.012. 
Maes, J., Meulenaer,B., Heerwynghels,P., Greyt,W., Eppe, G., Pauw, E., Huyghebaert,A. (2005). Removal of Dioxins and PCB from Fish Oil by Activated Carbon and Its Influence on the Nutritional Quality of the Oil. J Am Oil Chem Soc, 82(8), 593-597.

Menderez-Diaz, J. A., Gullon, M. (2006). Types of carbon adsorbents and their production. Interface Sci and technol, 7, 1-48.

Mussatto, S. I., Roberto, I.C. (2001). Hydrolysate detoxification with activated charcoal for xylitol production by Candida guilliermondii. Biotech Lett, 23, 1681-1684. doi:10.1023/A:1012492028646.

Mohd, N.I., Gopal, K., Raoov, M., Mohamad, S., Yahaya, N., Lim, V., Zain, N.N.M. (2019). Evaluation of a magnetic activated charcoal modified with non-ionic silicone surfactant as a new magnetic solid phase extraction sorbent with triazine herbicides as model compounds in selected milk and rice samples. Talanta, 196, 217225. doi:10.1016/j.talanta.2018.12.043.

Naka, K., Watarai,S., Inoue,T.K., Kodama,Y., Oguma, K., Yasuda, T., Kodama, H. (2000). Adsorption Effect of Activated Charcoal on Enterohemorrbagic Escherichia coli. Public Health, 281285.

Nasehi S.M., A. S., Sarshar M. (2012). Removal of dark colored compounds from date syrup using activated carbon: A kinetic study. J Food Eng, 111, 490-495. doi:10.1016/j.jfoodeng.2012.02.037.

Ogungbenro, A. E., Quang,D.V., Ali, K., Mohammad, R.M., Zahra, A. (2018). Physical synthesis and characterization of activated carbon from date seeds for $\mathrm{CO}_{2}$ capture. $J$ Environ Chem Eng, 6, 4245-4252. doi:10.1016/j.jece.2018.06.030.

Olgun, B., Erdem, A., Asiltürk, M., Doğan, G. (2017). Nanopartikül Tutturulmuş Aktif Karbon ile Ortam Havasında Uçucu Organik Bileşik Gideriminin Değerlendirilmesi. VII. Ulusal Hava Kirliliği ve Kontrolü Sempozyumu, 1-3 Kasım 2017, Antalya, Türkiye, 830-841.

Ou, S., Luo,Y., Xue, F. ,HUang,C., Zhang, N., Liu, Z. (2007). Seperation and purification of ferulic acid in alkaline-hydrolysate from sugarcane bagasse by activated charcoal adsorption/anion macroporous resin exchange chromatography. $J$ Food Eng, 78, 1298-1304. doi:10.1016/j.jfoodeng.2005.12.037

Ozmak, M. (2010). Biyokütle Atıklarından Aktif Karbon Üretimi. Ankara Üniversitesi, Fen Bilimleri Enstitüsü, Kimya Mühendisliği Anabilim Dalı, Doktora Tezi, Ankara,Türkiye, 185s.

Ozsoy, H. D., Leeuwen, J.H. (2010). Removal of color from fruit candy waste by activated carbon adsorption. J Food Eng, 101, 106-112. doi:10.1016/j.jfoodeng.2010.06.018.

Qadeer, R., Rehan, A.H. (2002). A Study of the Adsorption of Phenol by Activated Carbon from Aqueous Solutions. Turk J Chem, 26, 357-361.

Quintela, S., Villaran, M. C., Armentia,I.L., Elejalde, E. (2013). Ochratoxin A removal in wine: A review. Food Control, 30, 439-445. doi:10.1016/j.foodcont.2012.08.014.

Reichardt, C., Utgennannt, S., Stahmann,K., Klepel, O. (2018). Highly stable adsorptive and covalent immobilization of Thermomyces lanuginosus lipase on tailor-made porous carbon material. Biochem Eng J, 138, 63-73. doi:10.1016/j.bej.2018.07.003.

Ridal, J., Brownlee, B., McKenna, G., Levac, N. (2001). Removal of Taste and Odour Compounds by Conventional Granular Activated Carbon Filtration. Water Qual Res J, 36(1). doi:10.2166/wqri.2001.003.

Preis, S., Klauson, D., Gregor, A., (2013). Potential of electric discharge plasma methods in abatement of volatile organic compounds originating from the food industry. $J$ Environ Manag, 114, 125-138. doi:10.1016/j.jenvman.2012.10.042.

Lakshmi, S.D., Avti., P. K., Hegde, G., (2018). Activated carbon nanoparticles from biowaste as new generation antimicrobial agents: A review. Nano-Struct \& Nano-Objects, 16, 306-321. doi:10.1016/j.nanoso.2018.08.001.

Safarik, I., Horska,K., Pospiskova,K., Safarikova, M. (2012). Magnetically Responsive Activated Carbons for Bio- and Environmental 
Applications. Int Rev of Chem Eng (I.RE.CH.E.), 4(3), 346-352.

Saffarionpour, S., Ottens,M. (2017). Recent Advances in Techniques for Flavor Recovery in Liquid Food Processing. Food Eng Rev. doi:10.1007/s12393-017-9172-8.

Soto, M. L., Moure,A., Dominguez,H., Parajo,J.C. (2011). Recovery, concentration and purification of phenolic compounds by adsorption: A review. J Food Eng, 105, 1-27. doi:10.1016/j.jfoodeng.2011.02.010.

Srinivasan, R., Sorial, G.A. (2011). Treatment of taste and odor causing compounds 2-methyl isoborneol and geosmin in drinking water: A critical review. $J$ Environ Sci, 23(1). doi:10.1016/S1001-0742(10)60367-1.

Suo, F., Liu, X., Li,C., Yuan, M., Zhang, B., Wang, J., Ma, Y., Lai, Z., Ji, M. (2019). Mesoporous activated carbon fromstarch for superior rapid pesticides removal. Int J Biol Macromol, 121, 806813. doi:10.1016/j.ijbiomac.2018.10.132.

Sühnholz, S., Kopinke, F., Weiner, B. (2018). Hydrothermal treatment for regeneration of activated carbon loaded with organicmicropollutants. Sci Total Environ, 644, 854-861. doi:10.1016/j.scitotenv.2018.06.395.

Tubia, I., Prasad, K., Perez-Lorenzo, E., Abadin, C., Zumarraga, M., Oyanguren, I., Barbero, F., Paredes, J., Arana, S. (2018). Beverage spoilage yeast detection methods and control technologies: A review of Brettanomyces. Int J
Food Microbiol, 283, 65-76. doi:10.1016/j.ijfoodmicro.2018.06.020.

Türkmen, Ş.N., (2015). Çeşitli meyve kabuklarından biochar üretim yöntemlerinin geliştirilmesi. Yıldız Teknik Üniversitesi, Fen Bilimleri Enstitüsü, Kimya Mühendisliği Anabilim Dalı, Yüksek Lisans Tezi, İstanbul, Türkiye, 81 s.

Udomkun, P., Innawong, B., Siasakul,C., Okafor, C. (2018). Utilization of mixed adsorbents to extend frying oil life cycle in poultry processing. Food Chem, 284, 225-229. doi:10.1016/j.foodchem.2017.12.070.

Wang, F., Liang,J., Wang,W. Fu,D., Xiao,W. (2017). A new and efficient method for purification of poly- $\gamma$ - glutamic acid from highviscosity fermentation broth. Trop J Pharm Res, 16(6), 1267-1275. doi:10.4314/tjpr.v16i6.9.

Yağmur, E., Turkoğlu, S., Banford, A., Aktaş, Z. (2017). The relative performance of microwave regenerated activated carbons on the removal of phenolic pollutants. J Cleaner Prod, 149, 11091117. doi:10.1016/j.jclepro.2017.02.188.

Yangui, A., Abderrabba, M. (2018). Towards a high yield recovery of polyphenols from olive mill wastewater on activated carbon coated with milk proteins: Experimental design and antioxidant activity. Food Chem, 262, 102-109. doi:10.1016/j.foodchem.2018.04.091. 